\section{A simple apparatus for thin-layer chromatography}

\author{
M. P. WALSH From the Department of Chemical \\ Pathology, Westminster Hospital Medical School, \\ London
}

Thin-layer chromatography was introduced by Stahl (1956) and has advantages over paper chromatography in speed, resolution, and smaller sample size. Also, the physical nature of the thin layer allows its treatment, where necessary, with strong acids and alkalis.

It has been found possible to construct a satisfactory, cheap, and simple apparatus for the preparation of thin layers on glass carrier plates, so bringing the cost of this technique within the financial outlay of any laboratory.

\section{APPARATUS}

CARRIER PLATES These are made by cutting a single sheet of glass into individual plates of dimensions 6 in. $\times$ 3 in. It is important to use the same sheet so that all carrier plates have a uniform thickness and allow even passage of the spreader when applying the thin layer.

BASEBOARD A base for the carrier plates is made from plywood 40 in. $\times 8$ in. $\times 1$ in. Along one length and one end is tacked quarter dowelling to provide an edge for the plates and for guiding the spreader when in use (Fig. 1).
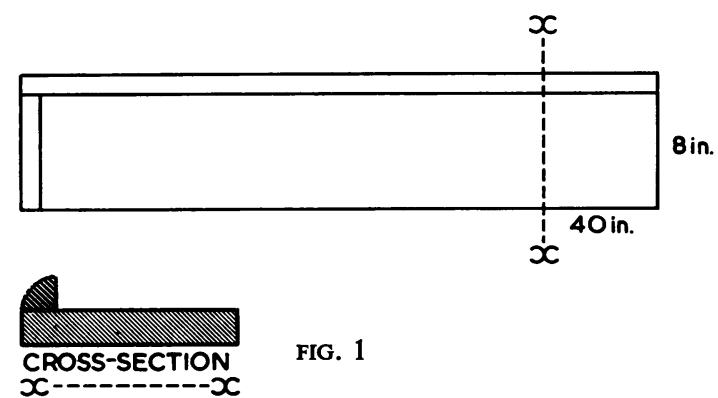

SPREADER The spreader is made from four 3 in. $\times 1 \frac{1}{2}$ in. glass microscope slides. Three slides are arranged to form a triangle and held in place with a rubber band (Fig. 2). They are then placed on a porcelain tile and two slides are pressed down while the third slide is given a clearance above the tile of $300 \mu$ using a feeler gauge. A fourth slide is placed as illustrated to give added strength and provide a convenient finger hold while using the spreader. Finally, epoxy resin glue (Holt's Twinbond) is sparingly applied to the slides. The spreader, on its tile, is then placed in an oven at $120^{\circ} \mathrm{C}$. for 30 minutes and may be

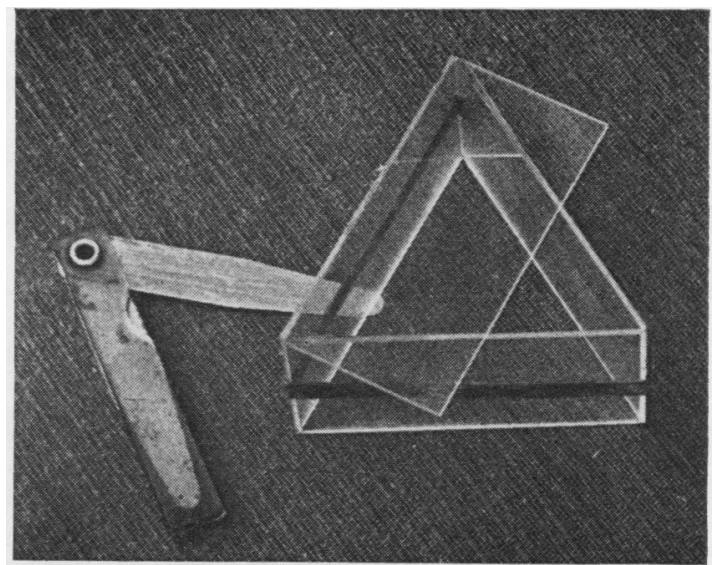

FIG. 2

used immediately, providing the clearance remains unaltered.

TEMPLATE A template is useful for spotting mixtures and can be made from perspex in the form of a bridge to span the plate. Notches are cut along one edge at $1 \mathrm{~cm}$. intervals to guide the pipette.

\section{PROCEDURE FOR SPREADING THE THIN LAYER}

The carrier plates are boiled in Pyroneg solution for half an hour to remove any grease. They are then washed, dried, and placed end to end along the baseboard.

The thin-layer medium is prepared according to the manufacturer's instructions and mixed with a mechanical stirrer to ensure homogeneity.

After waiting for half a minute for air bubbles to rise the mixture is poured into the spreader which rests on the end carrier plate. The spreader is now drawn along the line of carrier plates leaving an even layer of medium which corresponds in thickness to the depth of the gap in the third side of the spreader.

The plates are dried according to instructions, and any unwanted medium trimmed from the edges.

\section{CHROMATOGRAPHY}

This is most easily carried out by the ascending technique in a standard gas jar with the solvent in the bottom and the carrier plate placed inside.

The description applies to chromatography in one dimension but by adjusting the size of the spreader, plates, and tanks, two-dimensional and other chromatography procedures are possible.

\section{REFERENCE}

Stahl, E. (1956). Pharmazie, 11, 633. 